ISSN: 1858-4837; E-ISSN: 2598-019X

Volume 17, Nomor 1 (2022),

https://jurnal.uns.ac.id/region

DOI: 10.20961/region.v1711.31928

\title{
Hubungan keragaman guna lahan dalam urban compactness dengan ketersediaan lahan parkir di Kota Surakarta
}

\author{
The relationship between land use diversity in urban compactness and \\ availability of parking area in the City of Surakarta
}

\author{
F Ariani ${ }^{1}$, R P Utomo ${ }^{1}$, dan N Miladan ${ }^{1}$ \\ ${ }^{1}$ Program Studi Perencanaan Wilayah dan Kota, Fakultas Teknik, Universitas Sebelas \\ Maret
}

Corresponding author's email: feira.ariani@gmail.com

\begin{abstract}
Abstrak. Perkembangan kota membutuhkan ketersediaan lahan agar mampu memenuhi kegiatan perkotaan. Optimalisasi lahan diperlukan untuk menampung seluruh kegiatan yang terjadi dalam suatu kota. Salah satu caranya dengan penggunaan lahan campuran. Penerapan penggunaan lahan campuran juga dapat mendorong kota ke dalam bentuk kompak. Urban compactness merupakan indeks yang digunakan dalam mengukur kekompakan suatu kota. Salah satu komponen pembentuk urban compactness adalah penggunaan lahan campuran. Kota Surakarta merupakan salah satu kota di Indonesia dengan 66\% luas kawasannya digunakan untuk permukiman. Keragaman guna lahan yang tinggi dapat meningkatkan level kekompakan suatu kota. Penggunaan lahan campuran juga mempunyai hubungan dengan ketersediaan lahan parkir. Kegiatan parkir yang diberikan oleh beberapa penggunaan lahan merupakan cara untuk efisiensi ruang di daerah perkotaan. Penelitian ini bertujuan untuk mengetahui hubungan antara keragaman guna lahan dalam urban compactness dengan ketersediaan lahan parkir di Kota Surakarta. Penelitian ini menggunakan pendekatan deduktif positivistik dengan teknik analisis korelasi Spearman. Data dan informasi didapatkan dari dokumen institusional dan observasi lapangan. Hasil analisis menunjukan bahwa hubungan antara guna lahan campuran dalam urban compactness dengan ketersediaan lahan parkir di Kota Surakarta bernilai 0,584 yang termasuk dalam kategori berhubungan sedang. Hal tersebut berarti bahwa guna lahan campuran dalam urban compactness berkorelasi linear dengan ketersediaan lahan parkir yang ada.
\end{abstract}

Kata Kunci: Guna Lahan Campuran; Ketersediaan Lahan Parkir; Urban Compactness

Received: July 09, 2019; Accepted: July 22, 2019; Available online: January 31, 2022

Copyright $\odot$ 2022, REGION: Jurnal Pembangunan Wilayah dan Perencanaan Partisipatif 


\begin{abstract}
Urban development requires the land availability to facilitate urban activities. Land optimization is needed to accommodate all activities occurred in a city. One of the solutions is the mixed land-use. The implementation of mixed land-use can also drive the city into a compact form. Urban compactness is an index being used to measure the compactness of a city. One of the components that forms urban compactness is the mixed land-use. Surakarta is one of the cities in Indonesia which $66 \%$ of its area being used for settlements. High diversity of land-use can increase the level of compactness of a city. The mixed land-use is also related to the availability of parking areas. The parking area provided by multiple land-use, is a way for spatial efficiency in urban areas. This research aims to find out the relation between land-use diversity in urban compactness and the availability of parking area in Surakarta. This study used a positivistic deductive approach and it is supported by the Spearman correlation analysis technique. The data and information were obtained from institutional documents and field observations. The results of the analysis show that the correlation between mixed land-use in urban compactness and the availability of parking area in Surakarta is 0.584 which is included in the moderately related category. It can be concluded that the mixed land-use in urban compactness has linear correlation with the availability of parking area.
\end{abstract}

Keywords: Mixed Land-Use; Availability Of Parking Area; Urban Compactness

\title{
1. Pendahuluan
}

Industrialisasi dan modernisasi perkotaan membutuhkan sumber daya lahan dan sumber daya energi yang tinggi. Perkembangan kota yang pesat tentu akan berdampak pada peningkatan kebutuhan lahan untuk mewadahi perkembangan tersebut. Manusia memiliki ketergantungan mendasar terhadap lahan. Seiring dengan pertambahan jumlah penduduk, ketersediaan lahan semakin berkurang karena jumlah kebutuhan dan permintaan akan lahan sendiri semakin meningkat [1]. Penggunaan lahan campuran dibutuhkan untuk memfasilitasi semua kegiatan perkotaan. Integrasi penggunaan lahan dengan meningkatkan kedekatan kegiatan perkotaan adalah definisi dasar dari penggunaan lahan campuran [2]. Keragaman guna lahan biasanya digunakan sebagai solusi penggunaan lahan di luas lahan yang relatif kecil [3]. Banyaknya jenis fasilitas yang diberikan dapat menambah variasi dan vitalitas kawasan tersebut. Dalam hal ini, penggunaan lahan campuran merupakan salah satu komponen pembentuk urban compactness [2].

Roychansyah, Ishizaka, dan Omi [4] menjelaskan bahwa urban compactness meliputi kepadatan populasi, konsentrasi aktivitas, intensifikasi transportasi publik, ukuran kota dan aksesibilitas, serta target kesejahteraan sosial ekonomi. Penggunaan lahan masuk kedalam komponen konsentrasi aktivitas yang meliputi aktivitas pekerjaan dalam suatu area, fasilitas pekerjaan, permukiman dan hiburan dalam suatu area. Urban compactness mengacu pada beberapa konsentrasi pekerjaan dan perumahan serta keragaman guna lahan yang lebih besar [5]. Tingkat kekompakan dapat dilihat dari proses pemadatan dan intensifikasi lahan yang terjadi pada kawasan [6]. 
Terdapat beberapa pendekatan yang berbeda dalam pengukuran urban compactness. Tsai [7] mengelompokkan compactness berdasarkan bentuk perkotaan. Untuk tujuan memahami kesamaan dan perbedaan dimensi dari indeks urban compactness, diklasifikasikan sesuai dengan karakteristik yang dapat dibedakan dalam skala metropolitan. Tsai [7] menggunakan indikator size, density, degree of equal distribution dan degree of clustering. Coorey dan Lau [8] mengklasifikasikan urban compactness berdasarkan komponen kuantitatif dan kualitatif serta implikasinya terhadap keberlanjutan atau sustainability yang meliputi kepadatan, mix use, scale, dan permeability. Coorey dan Lau [8] menambahkan permeabilitas ke dalam indikator urban compactness yang ditentukan oleh building space index (BSI) atau tingkat kedekatan bangunan untuk melihat kedekatan guna lahan yang dapat diakses langsung dengan berjalan kaki. Guna lahan campuran atau mix use terdiri dari rasio guna lahan publik dan privat, guna lahan campuran, kelompok pendapatan campuran. Menurut Owen dalam Çalışkan [2] pendekatan yang berbeda pada pengukuran urban compactness menunjukkan bahwa kekompakan perkotaan meliputi skala di individual settlement dan neighbourhood.

Intervensi guna lahan dan manajemen transportasi yang buruk menyebabkan masalah kemacetan dan polusi udara. Densifikasi informal dapat meningkatkan kebutuhan akan jalan dan parkir karena meningkatnya jumlah kendaraan [9]. Cervero menjelaskan bahwa penggunaan lahan campuran akan meningkatkan kegiatan transit share sebesar 3 persen [10]. Sejumlah penelitian terbaru menunjukkan bahwa persediaan parkir dan penggunaan parkir per $1.000 \mathrm{ft}^{2}$ luas bangunan jauh lebih rendah di kawasan perkotaan dan pusat penggunaan campuran daripada di lokasi pinggiran kota [11,12]. Hal tersebut menunjukkan bahwa semakin tinggi penggunaan lahan campuran akan menurunkan jumlah lahan parkir yang tersedia.

Menurut data dari BPS Kota Surakarta [13], luas Kota Surakarta mencapai 44,04 km² yang terbagi menjadi lima kecamatan dan terdiri dari 51 kelurahan. Jumlah penduduk di Kota Surakarta sendiri berjumlah 570.876 jiwa dan tingkat kepadatan penduduk di Kota Surakarta pada tahun 2017 mencapai 11.718,78 jiwa/ $\mathrm{km}^{2}$. Sebagian besar lahan di Kota Surakarta digunakan sebagai tempat permukiman sebesar $66 \%$, sedangkan untuk kegiatan ekonomi juga mendominasi penggunaan lahan yaitu sekitar $17 \%$ dari total luas lahan yang ada di Kota Surakarta. Jika dilihat data penggunaan lahan dari BPS Kota Surakarta Tahun 2018, kelurahan di Kota Surakarta masing-masing telah memiliki guna lahan yang digunakan untuk fasilitas umum. Namun, luas lahan dan skala pelayanan masing-masing fasilitas tersebut berbeda. Hal ini yang menyebabkan tingkat keragaman guna lahan di Kota Surakarta berbeda-beda. Menurut Bernick \& Cervero [14] guna lahan campuran dapat memfasilitasi kebutuhan ruang harian sehingga dapat meminimalkan pergerakan menuju luar kawasan.

Setiap pergerakan melibatkan sistem jaringan dalam hal ini adalah jalan setiap harinya. Hal inilah yang menyebabkan adanya interaksi antara sistem kegiatan atau guna lahan dengan sistem jaringan karena hampir semua interaksi memerlukan perjalanan dan menghasilkan pergerakan arus lalu lintas [15]. Jika jarak antar guna lahan meningkat karena pemenuhan fasilitas tidak dapat dilayani dalam suatu kawasan, maka transportasi publik akan kehilangan 
kelayakannya dalam memenuhi kebutuhan kota. Akibatnya pergerakan cenderung didominasi oleh kendaraan pribadi. Oleh karena itu, sejalan dengan pendapat Thompson dalam Çalışkan [2] kebutuhan akan lahan parkir juga semakin meningkat. Masalah perparkiran mulai muncul ketika kebutuhan akan lahan parkir melebihi ketersediaan lahan parkir tersebut. Hal tersebut sering terjadi pada kota-kota di negara berkembang bahwa pada wilayah tertentu dan pada waktu tertentu kebutuhan parkir melebihi ketersediaan lahan parkir [16].

Parkir didefinisikan tempat khusus bagi kendaraan untuk berhenti. Menurut Peraturan Daerah Kota Surakarta No. 7 Tahun 2004 tentang Penyelenggaraan Tempat Khusus Parkir [17], pelataran parkir adalah lahan yang berbentuk pelataran milik pemerintah daerah dan bukan berada di tepi jalan umum yang ditetapkan sebagai tempat parkir. Di Kota Surakarta, pemenuhan parkir di luar badan jalan masih tergantung oleh masing-masing guna lahan. Sedangkan pemenuhan parkir di badan jalan menurut dokumen Tatralok Kota Surakarta Tahun 2009 [18], terdapat 18 jalan yang menggunakan badan jalan sebagai tempat parkir. Hal tersebut juga terlihat dari rambu parkir yang dipasang di setiap koridor jalan. Ketersediaan lahan parkir akan membawa dampak pada aktivitas perkotaan yang disebabkan oleh pergerakan lalu lintas dalam mencari tempat parkir di kawasan guna lahan tertentu [16]. Menurut Çalışkan [2], beberapa guna lahan yang terdapat pada kawasan yang kompak dapat menggunakan lahan parkir yang bersamaan secara berkala.

Terdapat beberapa penelitian yang mengangkat isu urban compactness, akan tetapi belum ditemukan penelitian yang melihat hubungan antara guna lahan campuran dalam urban compactness dengan ketersediaan lahan parkir. Penelitian Nuryanto [19] mengkaji tentang keterkaitan urban compactness dengan transportasi berdasarkan rasio kepemilikan kendaraan pribadi, tingkat VCR, dan LHR. Atianta [20] dan Istanabi [21] mengkaji tentang pengaruh urban compactness dengan pola pergerakan penduduk. Asidiqi [22] menemukenali pengaruh urban compactness terhadap tingkat ketersediaan ruang terbuka hijau. Oleh sebab itu, bertolak dari permasalahan yang terjadi dan perkembangan penelitian yang sudah dilakukan, penelitian ini memberikan kebaharuan dengan mengkaji apakah guna lahan campuran dalam urban compactness berhubungan dengan ketersediaan lahan parkir di Kota Surakarta.

\section{Metode}

Penelitian ini bertujuan untuk mengetahui hubungan antara keragaman guna lahan dalam urban compactness dengan ketersediaan lahan parkir di Kota Surakarta. Unit analisis yang digunakan dalam penelitian ini adalah 51 kelurahan yang ada di Kota Surakarta. Penelitian ini menggunakan pendekatan deduktif positivistik. Variabel yang digunakan dalam penelitian adalah variabel dari guna lahan campuran dalam urban compactness dan ketersediaan lahan parkir yang di dalamnya masih terdapat sub variabel sebagai elemen pembentuk variabel tersebut yang dapat ditinjau pada Tabel 1. 
Tabel 1. Variabel penelitian.

\begin{tabular}{|c|c|c|c|}
\hline Komponen & Variabel & Indikator & Definisi Operasional \\
\hline \multirow[t]{2}{*}{$\begin{array}{l}\text { Urban } \\
\text { compactness }\end{array}$} & $\begin{array}{l}\text { Guna lahan } \\
\text { campuran }\end{array}$ & $\begin{array}{l}\text { Proporsi luas } \\
\text { lahan fasilitas } \\
\text { umum }\end{array}$ & $\begin{array}{l}\text { Nilai perbandingan antara luas lahan sarana pendidikan, } \\
\text { sarana kesehatan, sarana peribadatan, sarana } \\
\text { perdagangan dan niaga, sarana kebudayaan dan } \\
\text { rekreasi, sarana ruang terbuka, taman dan lapangan } \\
\text { dibagi dengan luas total wilayah }\end{array}$ \\
\hline & & $\begin{array}{l}\text { Proporsi luas } \\
\text { lahan kawasan } \\
\text { perkantoran }\end{array}$ & $\begin{array}{l}\text { Nilai perbandingan antara luas lahan sarana } \\
\text { pemerintahan dan pelayanan dibagi dengan luas total } \\
\text { wilayah }\end{array}$ \\
\hline \multirow[t]{2}{*}{$\begin{array}{l}\text { Ketersediaan } \\
\text { lahan parkir }\end{array}$} & $\begin{array}{l}\text { Fasilitas } \\
\text { parkir }\end{array}$ & On street parking & $\begin{array}{l}\text { Luas lahan lokasi yang ditentukan sebagai tempat } \\
\text { pemberhentian kendaraan yang bersifat on street dalam } \\
\text { satuan } \mathrm{m}^{2}\end{array}$ \\
\hline & & Off street parking & $\begin{array}{l}\text { Luas lahan lokasi yang ditentukan sebagai tempat } \\
\text { pemberhentian kendaraan yang bersifat off street } \\
\text { dalam satuan } \mathrm{m}^{2}\end{array}$ \\
\hline
\end{tabular}

Metode pengumpulan data yang dilakukan menggunakan metode pengumpulan data primer dan sekunder. Pengumpulan data primer dilakukan untuk mengetahui luasan parkir di masingmasing kelurahan Kota Surakarta. Selain itu, untuk mengetahui luasan lahan parkir dilakukan dengan metode perhitungan luas lahan parkir dari citra satelit google earth dengan ketinggian antara 100-250 meter. Sedangkan, pengumpulan data sekunder dilakukan untuk mengetahui penggunaan lahan di Kota Surakarta yaitu data dari Badan Pertanahan Nasional (BPN) dan BAPPEDA Kota Surakarta. Luas lahan tiap penggunaan lahan didapatkan dari perhitungan peta shapefile penggunaan lahan dari BAPPEDA Kota Surakarta.

Teknik analisis data yang digunakan adalah analisis korelasi Spearman. Sebelum menggunakan analisis ini, variabel guna lahan campuran dalam urban compactness dan ketersediaan lahan parkir dilakukan analisis terlebih dahulu. Analisis variabel guna lahan campuran dalam urban compactness dilakukan analisis standarisasi menggunakan bantuan aplikasi SPSS karena data asli sub variabel yang diteliti mempunyai perbedaan ukuran satuan yang cukup besar. Standarisasi dilakukan terhadap sub variabel yang relevan ke dalam bentuk Z-skor [23,24]. Hasil dari perhitungan Z-skor ini kemudian dapat digunakan atau sebanding dengan perhitungan lain [25]. Selanjutnya, hasil perhitungan antara variabel urban compactness dan ketersediaan lahan parkir diurutkan dan dilakukan analisis menggunakan analisis korelasi Spearman. Hasil nilai dari guna lahan campuran dan ketersediaan lahan parkir harus diurutkan karena syarat analisis korelasi Spearman adalah menggunakan jenis data ordinal.

Nilai luas lahan yang didapatkan dari data sekunder kemudian dihitung proporsinya dengan total luas lahan wilayah. Masing-masing nilai hasil proporsi tersebut yang nantinya dilakukan standarisasi. Hasil dari analisis standarisasi selanjutnya dirata-rata dan menghasilkan tingkat guna lahan campuran dalam urban compactness. Sedangkan untuk ketersediaan lahan parkir, 
nilai luas lahan yang didapatkan dari pengukuran citra satelit google maps dijumlahkan antara luas lahan parkir on street dan luas lahan parkir off street. Hasil penjumlahan tersebut yang menghasilkan tingkat ketersediaan lahan parkir. Selanjutnya, antara tingkat guna lahan campuran dalam urban compactness dan tingkat ketersediaan lahan parkir dilakukan analisis korelasi Spearman. Hasil analisis ini menjelaskan kekuatan dan arah hubungan yang dihasilkan dari guna lahan campuran dan ketersediaan lahan parkir (lihat Gambar 1).

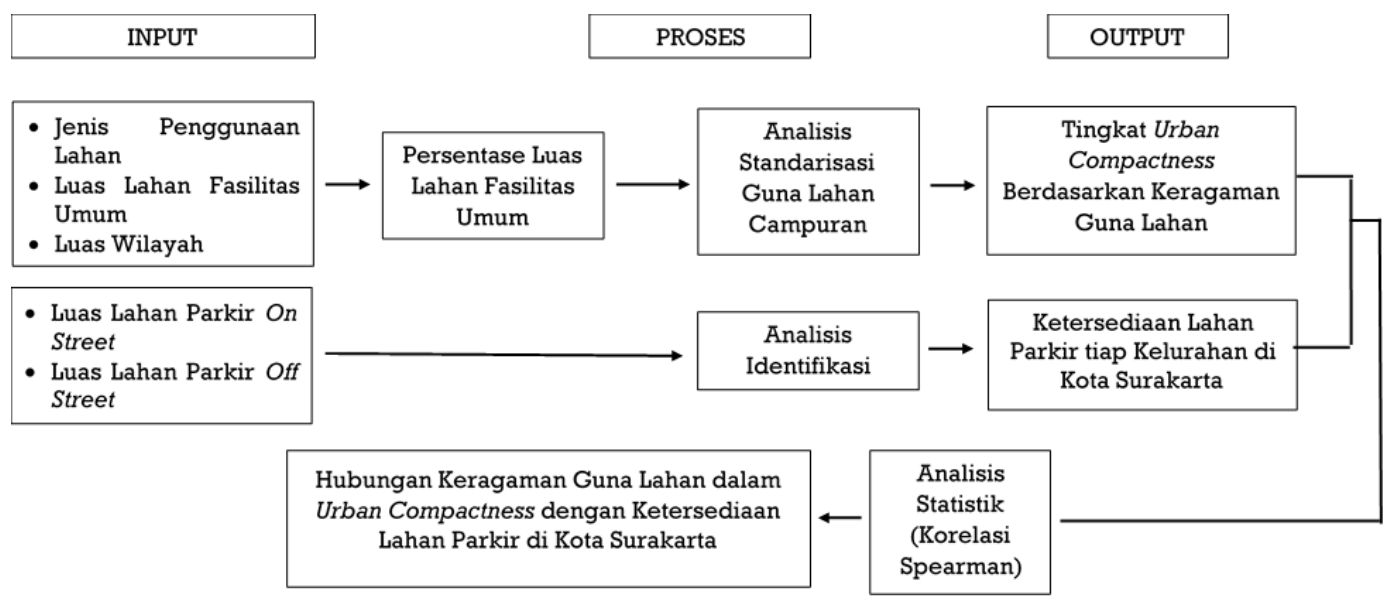

Gambar 1. Kerangka analisis penelitian.

\section{Hasil penelitian dan pembahasan}

\subsection{Keragaman guna lahan dalam urban compactness di Kota Surakarta}

Fungsi guna lahan campuran merupakan faktor pembentuk urban compactness. Guna lahan campuran dapat menunjukkan variasi penggunaan lahan untuk berbagai jenis kegiatan. Semakin banyak jenis kegiatan yang terjadi dan dapat dilakukan di suatu kawasan mengindikasikan bahwa kawasan tersebut mampu untuk memenuhi kebutuhan kegiatannya bahkan dapat dijadikan tarikan kawasan lain untuk melakukan kegiatan di dalamnya. Hal ini menandakan bahwa kawasan tersebut mempunyai nilai compactness yang lebih tinggi dari kawasan lainnya. Fasilitas umum yang digunakan dalam penelitian ini adalah sarana dasar permukiman sesuai dengan SNI 03-1733-2004 [26] tentang Perencanaan Lingkungan Perumahan di Perkotaan. Sarana dasar tersebut mencakup fasilitas pendidikan, kesehatan, peribadatan, perdagangan dan jasa, kebudayaan dan rekreasi, ruang terbuka hijau dan lapangan olahraga, serta fasilitas pemerintahan dan pelayanan. Semakin lengkap fasilitas yang disediakan oleh tiap wilayah maka semakin tinggi nilai urban compactness-nya. Guna lahan Kota Surakarta dapat ditinjau pada Gambar 2. 


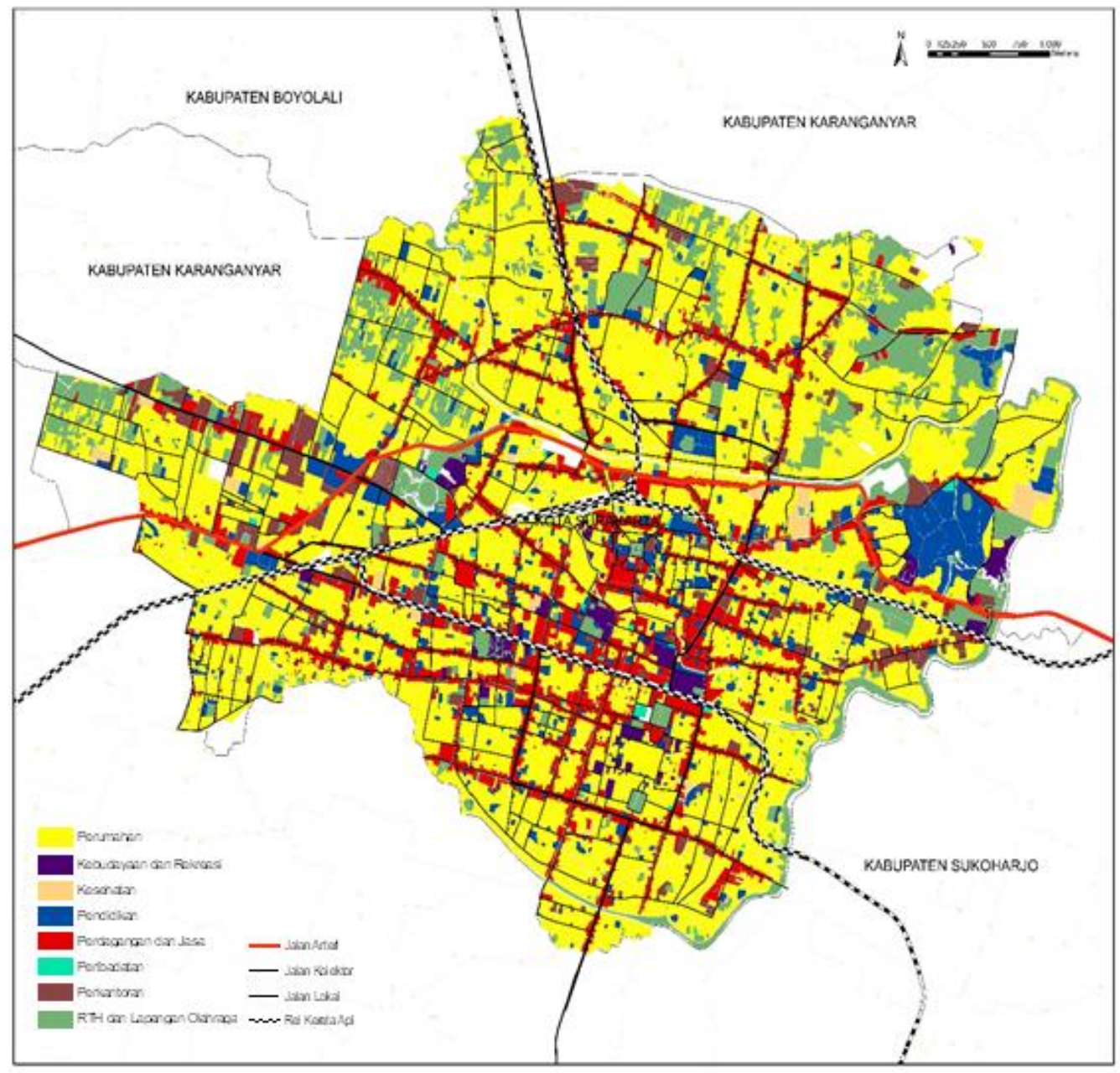

Gambar 2. Peta penggunaan lahan di Kota Surakarta.

Berdasarkan kasus di Kota Surakarta, semakin tinggi tingkat keragaman guna lahan pada suatu kawasan semakin tinggi pula tingkat urban compactness pada kawasan tersebut. Kawasan dengan tingkat urban compactness yang tinggi memiliki proporsi guna lahan yang tinggi dan berskala besar pada tiap guna lahannya seperti kawasan perdagangan, kawasan pendidikan, kawasan perdagangan dan jasa, kawasan kesehatan atau bahkan kawasan rekreasi. Kawasan dengan urban compactness yang rendah memiliki proporsi guna lahan yang kecil dan skala pelayanan yang kecil juga, bahkan ada beberapa guna lahan yang tidak terdapat pada kawasan tersebut. Menurut Nabil \& Abd Eldayem [27], terdapat dua jenis penggunaan lahan campuran yaitu guna lahan campuran dengan level vertikal dan guna lahan campuran dengan level horizontal. Guna lahan campuran dengan level vertikal adalah penggunaan lahan dengan dua atau lebih perbedaan fungsi pada satu bangunan. Sedangkan, penggunaan lahan campuran dengan level horizontal merupakan penggunaan lahan dengan dua atau lebih tipe fungsi yang terletak bersebelahan atau berdekatan satu sama lain dan terkoneksi oleh pedestrian dan kendaraan. Manaugh \& Kreider [25] mengklasifikasikan guna lahan campuran menjadi 3 kategori seperti pada Gambar 3. Pada model guna lahan nomor tiga, jarak yang dihasilkan tiap 
guna lahan lebih kecil dari model nomor 1 atau 2. Model nomor 3 juga dinyatakan lebih berpola menyebar karena hampir setiap penggunaan lahan berdekatan satu sama lain. Pada kasus penggunaan lahan di Kota Surakarta adalah menggunakan tipe penggunaan lahan dengan level horizontal (mixed land-use on the horizontal level) dan berpola fine-grained atau menyebar dan dapat dikatakan sesuai dengan model guna lahan campuran nomor 3 . Penggunaan lahan vertikal dengan lebih dari satu fungsi dalam satu bangunan masih jarang ditemukan di Kota Surakarta. Penyebaran fungsi guna lahan juga tidak mengelompok menjadi satu fungsi, namun lebih menyebar dalam satu kawasan.
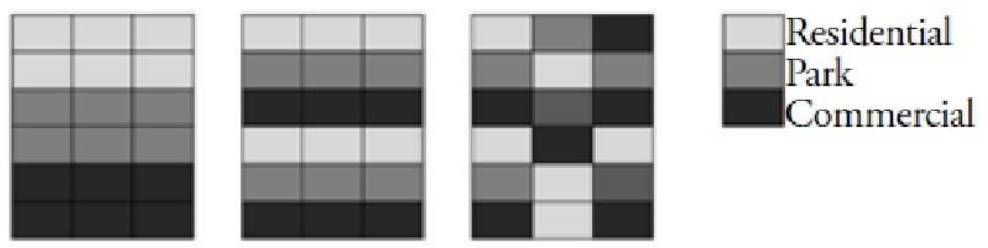

Gambar 3. Perbedaan jenis guna lahan campuran [25].

Penggunaan lahan pendidikan tertinggi berada di Kelurahan Jebres dengan luas lahan pendidikan yang cukup dominan dibandingkan dengan luas lahan pendidikan kelurahan lainnya karena di Kelurahan Jebres terdapat universitas yang skala pelayanannya sudah mencapai tingkat nasional. Penggunaan lahan kesehatan tertinggi juga berada di Kelurahan Jebres. Hal tersebut dibuktikan dengan adanya beberapa rumah sakit di Kelurahan Jebres yang cukup besar dan luasnya cukup signifikan dibandingkan dengan luas lahan sarana kesehatan di kelurahan lainnya seperti Rumah Sakit Dr. Moewardi, Rumah Sakit Hermina, dan Rumah Sakit Jiwa. Penggunaan lahan peribadatan tertinggi berada di Kelurahan Kauman karena terdapat masjid yang juga menjadi daya tarik wisata Kota Surakarta yaitu Masjid Agung. Lahan perdagangan dan jasa merupakan lahan yang sangat berpengaruh dalam rantai ekonomi kawasan dan penggunaan lahan perdagangan dan jasa tertinggi berada di Kelurahan Kadipiro. Hal tersebut terlihat karena Kelurahan Kadipiro mempunyai luas wilayah yang cukup tinggi sehingga banyak terdapat kegiatan perdagangan dan jasa di kawasan tersebut. Penggunaan lahan kebudayaan dan rekreasi tertinggi berada di Kelurahan Jebres karena terdapat Taman Satwataru Jurug dengan luas wilayah yang tinggi. Nilai luas lahan kebudayaan dan rekreasi juga cukup dominan di Kelurahan Jebres jika dibandingkan dengan kelurahan lain. Penggunaan lahan ruang terbuka hijau dan lapangan olahraga tertinggi berada di Kelurahan Mojosongo karena masih terdapat banyak terdapat lahan kosong yang belum dimanfaatkan. Nilai luas lahan ruang terbuka dan lapangan olahraga terbanyak masih di dominasi di kawasan Surakarta bagian utara seperti Kelurahan Mangkubumen, Kelurahan Manahan, Kelurahan Sumber, Kelurahan Kadipiro, Kelurahan Banyuanyar, dan Kelurahan Jebres. Hal tersebut karena Kota Surakarta memang mempunyai kecenderungan pemekaran wilayah ke bagian selatan. Penggunaan lahan pemerintahan dan pelayanan tertinggi berada di Kelurahan Kerten karena terdapat banyak kantor-kantor pelayanan pemerintahan. Tingkat keragaman guna lahan tersebut kemudian diurutkan per kelurahan seperti pada Tabel 2. 
Tabel 2. Tingkat keragaman guna lahan dalam urban compactness per kelurahan di Kota Surakarta.

\begin{tabular}{llc}
\hline Kecamatan & \multicolumn{1}{c}{ Kelurahan } & Urutan \\
\hline Jebres & Kepatihan Kulon & 37 \\
& Kepatihan Wetan & 24 \\
& Sudiroprajan & 27 \\
& Gandekan & 40 \\
& Sewu & 46 \\
& Pucangsawit & 38 \\
& Jagalan & 30 \\
& Purwodiningratan & 22 \\
& Tegalharjo & 34 \\
& Jebres & 1 \\
& Mojosongo & 3 \\
& Joyotakan & 50 \\
& Danukusuman & 43 \\
& Serengan & 45 \\
& Tipes & 42 \\
& Kratonan & 44 \\
& Jayengan & 35 \\
& Kemlayan & 41 \\
& Joyosuran & 49 \\
& Semanggi & 28 \\
& Pasar Kliwon & 31 \\
& Baluwarti & 21 \\
& Gajahan & 32 \\
& Kauman & 20 \\
& Kampung Baru & 9 \\
& Kedung Lumbu & 6 \\
& Sangkrah & \\
& &
\end{tabular}

\begin{tabular}{clc}
\hline Kecamatan & \multicolumn{1}{c}{ Kelurahan } & Urutan \\
\hline Laweyan & Pajang & 13 \\
& Laweyan & 51 \\
& Bumi & 36 \\
& Panularan & 17 \\
& Sriwedari & 16 \\
& Penumping & 11 \\
& Purwosari & 7 \\
& Sondakan & 29 \\
& Kerten & 5 \\
& Jajar & 8 \\
& Karangasem & 15 \\
Manjarsari & Mangkubumen & 19 \\
& Timuran & 23 \\
& Keprabon & 11 \\
& Ketelan & 33 \\
& Punggawan & 39 \\
& Kestalan & 47 \\
& Setabelan & 12 \\
& Gilingan & 14 \\
Manahan & 2 \\
& Sumber & 26 \\
& Nusukan & 18 \\
& Kadipiro & 4 \\
& Banyuanyar & 25 \\
\hline & & \\
& &
\end{tabular}

\subsection{Ketersediaan lahan parkir di Kota Surakarta}

Di Kota Surakarta penempatan lokasi parkir di ruang milik jalan adalah di fungsi jalan kolektor dan lokal. Terdapat 18 jalan di Kota Surakarta yang ditetapkan oleh Dinas Perhubungan Kota Surakarta yang dapat digunakan sebagai lahan parkir. Hal tersebut juga dikarenakan oleh guna lahan di sekitar jalan kolektor maupun jalan lokal adalah fungsi guna lahan perdagangan dan jasa. Jenis parkir on street memiliki sudut parkir yang berbeda-beda sesuai dengan lebar jalan. Sudut parkir tersebut yang membuat luasan lahan parkir di ruang milik jalan Kota Surakarta berbeda-beda. Jumlah titik lokasi parkir di setiap ruas jalan berbeda-beda tergantung dari fungsi tata guna lahan yang ada di jalan tersebut. Tata guna lahan dengan aktivitas komersial dan pasar menjadi lokasi potensial parkir, baik dimanfaatkan oleh pengunjung guna lahan tersebut maupun oleh pegawai/pemilik guna lahan tersebut.

Sedangkan lahan parkir off street masih disediakan oleh tiap guna lahan untuk memfasilitasi pergerakan masyarakat. Lahan parkir ini dikelola oleh swasta pemilik guna lahan tersebut. Jenis guna lahan yang menyediakan lahan parkir di luar ruang milik jalan ini diantaranya guna lahan perdagangan dan jasa, perkantoran, kesehatan, pendidikan, dan tempat rekreasi. Parkir 
ini disediakan oleh tiap guna lahan karena memang tujuan utamanya adalah agar lokasi parkir sedekat mungkin dengan tujuan perjalanan. Jika lokasi parkir jauh dengan lokasi tujuan perjalan maka orang akan beralih ke tujuan lain [15]. Penerapan sistem shared parking atau lahan parkir bersama di Kota Surakarta belum banyak diaplikasikan. Hal tersebut karena pada dasarnya jenis bangunan yang ada di Kota Surakarta adalah jenis bangunan tunggal. Jenis bangunan ini memerlukan lahan parkir di tiap-tiap bangunan dan masyarakat cenderung menggunakan kendaraan pribadinya untuk melakukan pergerakan menuju bangunan pada guna lahan lain.

Tabel 3. Tingkat ketersediaan lahan parkir per kelurahan di Kota Surakarta.

\begin{tabular}{|c|c|c|c|c|c|}
\hline Kecamatan & Kelurahan & Urutan & Kecamatan & Kelurahan & Urutan \\
\hline \multirow[t]{11}{*}{ Jebres } & Kepatihan Kulon & 44 & Laweyan & Pajang & 5 \\
\hline & Kepatihan Wetan & 34 & & Laweyan & 47 \\
\hline & Sudiroprajan & 31 & & Bumi & 45 \\
\hline & Gandekan & 51 & & Panularan & 38 \\
\hline & Sewu & 48 & & Sriwedari & 6 \\
\hline & Pucangsawit & 39 & & Penumping & 9 \\
\hline & Jagalan & 50 & & Purwosari & 3 \\
\hline & Purwodiningratan & 33 & & Sondakan & 36 \\
\hline & Tegalharjo & 23 & & Kerten & 12 \\
\hline & Jebres & 1 & & Jajar & 28 \\
\hline & Mojosongo & 25 & & Karangasem & 27 \\
\hline \multirow[t]{8}{*}{ Serengan } & Joyotakan & 49 & Banjarsari & Gilingan & 4 \\
\hline & Danukusuman & 35 & & Manahan & 14 \\
\hline & Serengan & 32 & & Sumber & 29 \\
\hline & Tipes & 13 & & Nusukan & 16 \\
\hline & Kratonan & 41 & & Kadipiro & 19 \\
\hline & Jayengan & 24 & & Banyuanyar & 40 \\
\hline & Kemlayan & 17 & & Mangkubumen & 8 \\
\hline & & & & Timuran & 10 \\
\hline \multirow[t]{8}{*}{ Pasar Kliwon } & Joyosuran & 37 & & Keprabon & 30 \\
\hline & Semanggi & 21 & & Ketelan & 20 \\
\hline & Pasar Kliwon & 42 & & Punggawan & 26 \\
\hline & Baluwarti & 46 & & Kestalan & 15 \\
\hline & Gajahan & 7 & & Setabelan & 18 \\
\hline & Kauman & 11 & & & \\
\hline & Kampung Baru & 22 & & & \\
\hline & Kedung Lumbu & 2 & & & \\
\hline
\end{tabular}

Dapat dilihat dalam Tabel 3 bahwa ketersediaan lahan parkir tertinggi berada pada Kelurahan Jebres. Jika dilihat dari analisis-analisis sebelumnya, Kelurahan Jebres merupakan kelurahan dengan tingkat keragaman guna lahan tertinggi di Kota Surakarta. Hal tersebut membutuhkan banyak lahan parkir untuk tiap satuan guna lahannya dilihat dari karakteristik Kota Surakarta. Sedangkan tingkat ketersediaan lahan parkir terendah berada pada Kelurahan Gandekan karena pada Kelurahan Gandekan termasuk ke dalam tingkat urban compactness berdasarkan kepadatan tertinggi di Kota Surakarta. Hal tersebut yang membuat Kelurahan Gandekan lebih rendah dalam hal ketersediaan lahan parkir dibanding dengan kelurahan lainnya. 


\subsection{Hubungan keragaman guna lahan dalam urban compactness dengan ketersediaan lahan parkir di Kota Surakarta}

Setiap guna lahan membutuhkan lahan parkir untuk tempat pemberhentian kendaraan. Kegiatan parkir yang diberikan oleh beberapa penggunaan lahan merupakan cara untuk efisiensi ruang di daerah perkotaan. Misalnya dalam kombinasi guna lahan kantor dan permukiman dari penggunaan campuran, warga dan pihak luar kantor bisa menggunakan ruang parkir secara berkala setiap harinya. Pola aktivitas tersebut dapat mengecilkan skala pusat kegiatan sebanyak 25 persen. Dengan kata lain, kekompakan fisik dapat tersedia dengan konfigurasi kedekatan guna lahan baik secara vertikal maupun horizontal $[2,14]$. Jadi dapat disimpulkan bahwa guna lahan campuran dan ketersediaan lahan parkir mempunyai hubungan yang negatif, artinya semakin tinggi tingkat keragaman guna lahan, maka semakin rendah tingkat ketersediaan lahan parkir yang ada.

Namun, yang terjadi di Kota Surakarta adalah sebaliknya. Semakin tinggi tingkat keragaman guna lahan maka ketersediaan lahan parkir akan semakin meningkat juga. Hal tersebut karena sistem compactness di Kota Surakarta belum berjalan secara optimal. Terdapat tiga jenis keragaman guna lahan menurut Schwanke dalam Al-Shawabkeh dan Alhaddad [3] yaitu high rise with low coverage (keragaman guna lahan secara vertikal), low rise with high coverage (keragaman guna lahan secara horizontal) dan medium rise with medium coverage. Kota Surakarta masuk ke dalam kategori keragaman guna lahan secara horizontal. Skala analisis dalam penelitian ini adalah kelurahan dan keragaman guna lahan yang ada di masing-masing kelurahan terbentuk secara horizontal. Terdapat beberapa jenis guna lahan yang disediakan oleh tiap administrasi kelurahan pada suatu luasan kelurahan. Hasil dari olahan data analisis statistik untuk guna lahan campuran didapatkan hasil bahwa nilai korelasi antara guna lahan campuran dengan ketersediaan lahan parkir bernilai 0,584 yang termasuk dalam kategori berhubungan sedang serta arah korelasi yang positif atau searah yang artinya semakin tinggi tingkat keragaman guna lahan maka semakin tinggi pula nilai ketersediaan lahan parkir (lihat Gambar 4). Kekuatan hubungan antara guna lahan campuran dengan ketersediaan lahan parkir bernilai 0,000 atau lebih kecil dari 0,01 yang berarti hubungan antara guna lahan campuran dengan ketersediaan lahan parkir dapat dikatakan signifikan. Hasil ini berbeda dengan teori hubungan guna lahan campuran dan ketersediaan lahan parkir yang ada karena di Kota Surakarta sendiri masih ada kecenderungan sprawl pada pinggiran kota yang menyebabkan banyak pergerakan dari kawasan tersebut ke kawasan di Kota Surakarta. Sarana transportasi publik juga belum menjangkau hingga kawasan pinggiran Kota Surakarta sehingga pergerakan masih didominasi oleh kendaraan pribadi serta terdapat beberapa fasilitas umum di Kota Surakarta yang mempunyai skala pelayanan regional yang menyebabkan lahan parkir semakin meningkat di kawasan Kota Surakarta. 


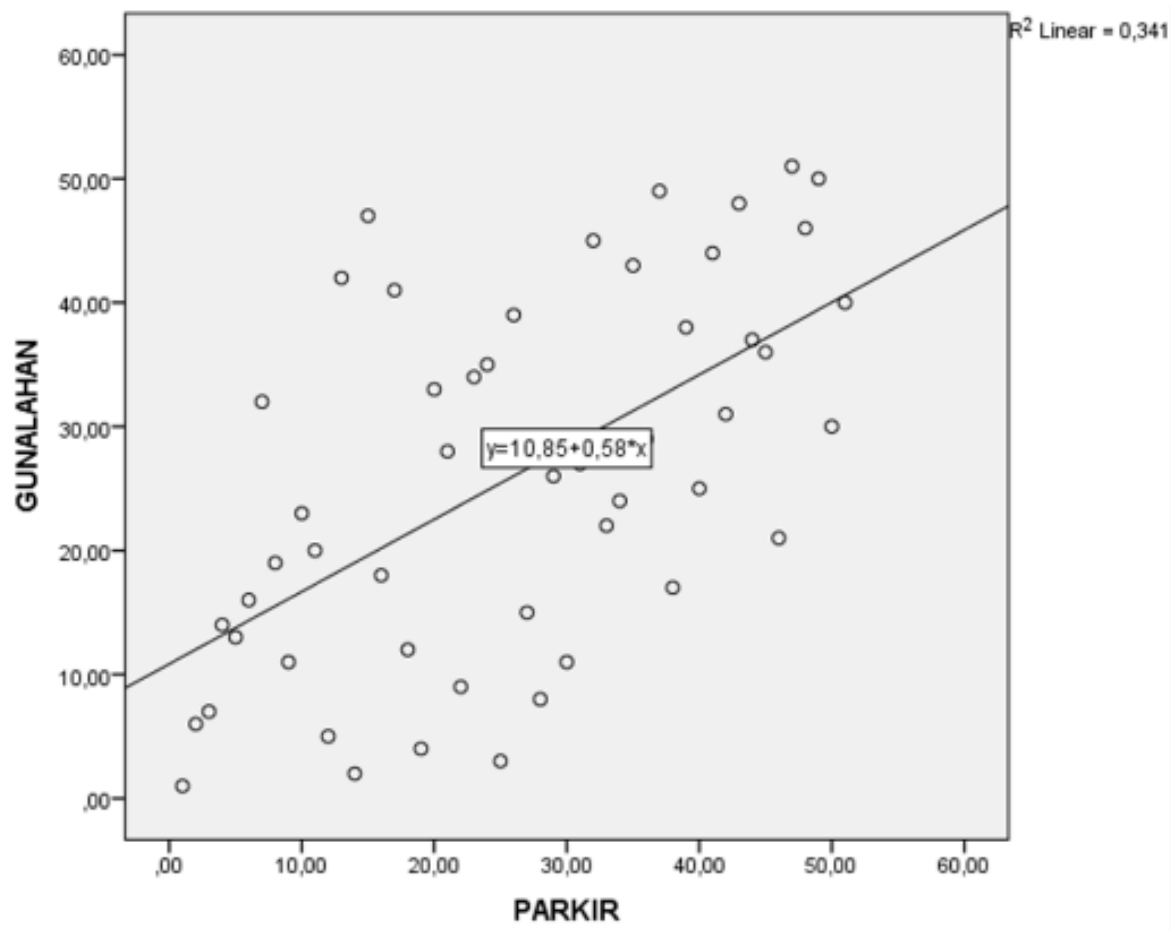

Gambar 4. Grafik hubungan keragaman guna lahan dengan ketersediaan parkir di Kota Surakarta.

\section{Kesimpulan}

Di Kota Surakarta, semakin tinggi tingkat guna lahan campuran maka tingkat ketersediaan lahan parkir akan meningkat juga. Hal ini karena di Kota Surakarta masih didominasi oleh penggunaan lahan dengan jenis bangunan tunggal sehingga tiap bangunan tersebut harus menyediakan lahan parkir sendiri. Berdasarkan hasil analisis, nilai hubungan antara guna lahan campuran dalam urban compactness dengan ketersediaan lahan parkir adalah 0,584 yang termasuk kategori berhubungan sedang. Secara umum hasil yang didapatkan dari penelitian ini berbeda dengan teori yang ada. Di Kota Surakarta masih terdapat kesenjangan guna lahan antara kawasan bagian utara dan selatan karena adanya pemusatan aktivitas dan skala pelayanan fasilitas yang berbeda. Selain itu, di Kota Surakarta sendiri masih ada kecenderungan sprawl pada pinggiran kota yang menyebabkan banyak pergerakan di kawasan tersebut menuju ke kawasan di Kota Surakarta. Dari segi guna lahan di Kota Surakarta juga banyak yang mempunyai skala pelayanan regional yang dapat melayani kawasan sekitarnya. Hal inilah yang menyebabkan ketersediaan lahan parkir meningkat pada tiap guna lahan untuk memfasilitasi pergerakan dari luar daerah tersebut.

\section{Ucapan Terima Kasih}

Penulis ingin mengucapkan terima kasih kepada Program Studi Perencanaan Kota dan Wilayah, Fakultas Teknik, Universitas Sebelas Maret yang telah memfasilitasi kegiatan penelitian ini yang merupakan bagian dari penelitian "Hubungan Urban Compactness dengan Ketersediaan Lahan Parkir di Kota Surakarta". Penulis juga ingin mengucapkan terima kasih kepada instansi 
pemerintahan Kota Surakarta yang telah membantu memberikan data dan informasi untuk kegiatan penelitian ini.

\section{Referensi}

[1] Baja S. Perencanaan Tata Guna Lahan dan Pengembangan Wilayah: Pendekatan Spasial dan Aplikasinya. Yogyakarta: Penerbit Andi; 2012.

[2] Çalışkan O. Urban Compactness: A Study of Ankara Urban Form. Middle East Technical University, 2004.

[3] Al-Shawabkeh RK, Alhaddad MI. High Density Mixed Use as an Effective Scheme in Applying Sustainable Urban Design Principles in Amman, Jordan. Int J Humanit Soc Sci 2017;7:57-78.

[4] Roychansyah MS, Ishizaka K, Omi T. Considerations of Regional Characteristics for Delivering City Compactness: Case of Studies of Cities in the Greater Tokyo Area and Tohoku Region, Japan. J Asian Archit Build Eng 2005;4:339-46. https://doi.org/10.3130/jaabe.4.339.

[5] Rahnam MR, Wyatt R, Heydari A. What Happened From 2001 to 2011 in Melbourne? Compactness Versus Sprawl. Sustain Cities Soc 2015;19:109-20. https://doi.org/10.1016/j.scs.2015.07.001.

[6] Xie Y. Urban Compaction and Its Impacts on Urban Development in China: A Case Study of Beijing. University of Hong Kong, 2010. https://doi.org/10.5353/th_b4718573.

[7] Tsai YH. Quantifying Urban Form: Compactness Versus "Sprawl." Urban Stud 2005;42:141-61. https://doi.org/10.1080/0042098042000309748.

[8] Coorey SBA, Lau SSY. Urban Compactness and Its Progress Towards Sustainability: the Hong Kong Scenario. Sustain Dev Plan II 2005;1:87-97.

[9] Acioly CC. Can Urban Management Deliver the Sustainable City? Guided Densification in Brazil versus Informal Compactness in Egypt. In: Jenks M, Burgess R, editors. Compact Cities Sustain. Urban Forms Dev. Ctries., London: Spoon Press; 2004, p. 127-40.

[10] Cervero R. Land Uses and Travel at Suburban Activity Centers. Transp Q 1991;45:47991.

[11] Marshall WE, Garrick NW. Parking at Mixed-Use Centers in Small Cities. Transp Res Rec 2006;1977:164-71. https://doi.org/10.1177/0361198106197700119.

[12] McCahill C, Haerter-Ratchford J, Garrick N, Atkinson-Palombo C. Parking in Urban Centers: Policies, Supplies, And Implications in Six Cities. Transp Res Rec 2014;2469:49-56. https://doi.org/10.3141/2469-06.

[13] Badan Pusat Statistik Kota Surakarta. Kota Surakarta Dalam Angka 2018. Surakarta: BPS Kota Surakarta; 2018.

[14] Bernick M, Cervero R. Transit Villages in the 21st Century. New York: McGraw-Hill; 1997.

[15] Tamin OZ. Perencanaan dan Permodelan Transportasi. Bandung: ITB Press; 2000.

[16] Rye T, Koglin T. Parking Management. Transp Sustain 2014;5:157-84. https://doi.org/10.1108/S2044-994120140000005027.

[17] Peraturan Daerah Kota Surakarta No. 7 Tahun 2004 tentang Penyelenggaraan Tempat Khusus Parkir n.d.

[18] Dinas Perhubungan Kota Surakarta. Tataran Transportasi Lokal (TATRALOK) Kota 
Surakarta tahun 20092009.

[19] Nuryanto AD. Identifikasi Urban Compactness di Wilayah Metropolitan Semarang. Institut Teknologi Bandung, 2008.

[20] Atianta L. Pengaruh Urban Compactness terhadap Pola Pergerakan Penduduk Kota Yogyakarta. Universitas Gadjah Mada, 2014.

[21] Istanabi T. Hubungan Urban Compactness dengan Pola Pergerakan Penduduk Kota Surakarta. Universitas Sebelas Maret, 2015.

[22] Asidiqi H, Utomo RP, Soedwiwahjono. Pengaruh Urban Compactness terhadap Tingkat Ketersediaan Ruang Terbuka Hijau di Kawasan Solo Baru. Arsitektura 2017;15:27-34.

[23] Alwi W, Hasrul M. Analisis Klaster Untuk Pengelompokkan Kabupaten/Kota Di Provinsi Sulawesi Selatan Berdasarkan Indikator Kesejahteraan Rakyat. J MSA (Matematika Dan Stat Serta Apl 2018;6:35-42. https://doi.org/10.24252/msa.v6i1.4782.

[24] Ary M. Pengklasifikasian Karakteristik Mahasiswa Baru dalam Memilih Program Studi Menggunakan Analisis Cluster. J Inform 2015;II:181-8.

[25] Manaugh K, Kreider T. What Is Mixed use? Presenting An Interaction Method For Measuring Land Use Mix. J Transp Land Use 2013;6:63-72. https://doi.org/10.5198/jtlu.v6i1.291.

[26] SNI 03-1733-2004 Tata Cara Perencanaan Lingkungan Perumahan di Perkotaan. n.d.

[27] Nabil NA, Eldayem GEA. Influence of Mixed Land-Use on Realizing the Social Capital. HBRC J 2015;11:285-98. https://doi.org/10.1016/j.hbrcj.2014.03.009. 